\title{
Research on the Exploitation Strategy of Tourism and Cultural Resources in Southwest Minority Regions
}

\author{
Jie Yang, Wenjun $\mathrm{He}$ \\ Sichuan Tourism College, Chengdu, Sichuan, 610100, China
}

\begin{abstract}
The first part of this article is a detailed introduction of the characteristics of tourism cultural resources in the southwest minority areas. The second part mainly analyzes the significance of the development of tourism cultural resources in the southwest minority areas, and it can better promote the rapid development of local society and economy; the third part is the study of the development strategy of tourism cultural resources in the southwest minority areas. The third part is about the guiding ideology, development goals and development strategies. It is a valuable reference for the development of tourism cultural resources in the southwest minority areas of China and it can improve the rationality and scientific of its development.
\end{abstract}

Keywords: exploitation strategy, tourism and cultural resources, southwest minority regions

\section{Introduction}

With the rapid social and economic development, people's living standards and quality have been significantly improved, people are met in the material life, gradually began to pursue spiritual and cultural satisfaction, tourism as a form of entertainment, more and more people's welcome. The south-western region of China is rich in natural scenery and ethnic minorities. It displays rich and colourful national characteristics and strengthens the development of local tourism cultural resources. It can not only meet people's spiritual and cultural needs, but also promote local social and economic development. 


\section{The characteristics of the tourism cultural resources in the southwest minority areas}

The tourism cultural resources in ethnic areas refer to the national cultural factors that can attract tourists, which mainly include natural resources, historical and cultural resources, production and life style, living customs and so on. For the ethnic areas of tourism and cultural resources, the full display of a variety of national cultural patterns, from the point of view of the material state, there are residential buildings, historical sites and landscape scenery; from the institutional point of view, there are Ethnic customs and religious ceremonies; from the conceptual point of view, there are ritual taboos and singing and dancing. Especially in southwest Chinese ethnic minority areas, is a gathering area of ethnic minorities, such as Dong, Miao, Tujia, with strong and unique national tourism and cultural resources.

\subsection{It is rich in historical and cultural resources}

Chinese south-western region has a rich historical and cultural heritage, a variety of cultural relics, such as the ancient city of Liye, the Longshan cultural sites, the tomb of the ancient capital of the ancient town of the Millennium, Wangcun, Phoenix, etc., whether unearthed cultural relics, Ancient buildings, Huang Yongyu new home, former residence of Shen Congwen, all reflect a strong historical and cultural atmosphere, rich in resources.

\subsection{It has unique ethnic customs}

As the south-western region of China is a gathering area for ethnic minorities, the majority of them are mainly Miao and Tujia, about $80 \%$ of the total population, the people of these ethnic minorities have been living here, plus in the Remote areas, but also for the hilly landforms, the traffic occlusion period gradually formed a unique production and living habits, and bring a touch of mystery, even in modern society, can also be relatively complete preservation of the local unique Literature and art, residential architecture, ritual religion, clothing diet, folk customs and other characteristics of cultural resources [2]. Such as Diaojiao Lou, ancient architecture and other unique residential areas, the Festival, Festival Sa, Niu Festival, Daughter Club, the Palestinian Festival and other traditional festivals, male and female antiphonal song, Mao Gu Si dance and other national cultural festivals, Beautiful stories, folklore, ethnic minority embroidery and clothing and so on. For these national cultures, are in the long-term life production and cultural integration, collision, and the final formation of the national culture, has become a modern national cultural tourism resources treasure, colourful, full-bodied. 


\subsection{The unique natural landscape}

Due to geographical environment is more remote occlusion, by the urbanization and the construction of the impact of industrial construction is relatively small, the natural landscape to retain the integrity of the natural landscape to retain the integrity of the natural landscape of the southwest of China is a karst landform, Bashan Chu water, waterfalls hanging, ancient trees, towering rocks, , Which for the development of tourism and cultural resources to provide a good foundation and prerequisite. For now, the more famous are Zhangjiajie Scenic Area, a small South China Sea landscape, Fanjingshan, Shennongjia, Meng Dong River and other natural landscape [3]. Therefore, Chinese southwestern region can be built into a set of national culture, natural ecology, Qi Shan different water as one of the tourist destination.

\section{The significance of strengthening the southwest national tourism and cultural resources development}

\subsection{Adapt to the current development of the tourism industry}

In the process of tourism development, cultural resources play an important role, while the presence of cultural resources can also greatly increase the tourism charm. For human beings, always full of curiosity about new things, in this psychological drive, more hope to understand and understand the exotic culture, which is the root cause of the formation of tourism. Tourism itself is a way of exploring different cultures and different cultures, and it is a process of satisfying cultural needs. This means that tourism is essentially to meet their own cultural and spiritual needs, and related to international exchanges, social, political and economic content of the popular activities [4]. All along, the tourism is the tourist of the cultural point and starting point, but also the soul of its development.

\subsection{It can effectively promote the development of local tourism industry}

For the development of any industry, the degree of resource utilization and development plays a decisive role, on the development of tourism and the increase of tourism resources development is very necessary and critical. As the southwest region is located in remote areas, economic development and urban construction process are relatively slow, to strengthen the excavation of characteristic resources, give full play to the local cultural tourism resources, can greatly promote the rapid development of local society and economy. On the one hand, can effectively improve the cultural quality of tourism products, and then attract more tourists, increase traffic; the other hand, more diversified tourism consumption, tourism consumption level has been significantly improved. For example, some of the national characteristics of the temple temples or villas open to tourists and carry out the appropriate cultural and entertainment projects, which will greatly increase the attractiveness of tourists. In addition, due to its 
geographical advantages in the southwest region, to open up foreign tourists, and gradually developed into an international tourism.

\subsection{It contributes to improving the quality of life of the local population}

The reason is that the local people mainly rely on agricultural income, but with the change of national policy, the local people's living standard is the main reason for this phenomenon. The labour force gradually appeared the excess phenomenon. As for the tourism industry, it can provide employment opportunities for the local residents, at the same time promote the development of other industries, people's economic income increased significantly, while capital flow, information flow, logistics and traffic increase greatly increased the local of the degree of convenient transportation, and thus achieve the effective development of industrial development space.

\subsection{Better protect the local cultural resources of the nation}

The development of tourism cultural resources in the ethnic areas can be enhanced by raising local awareness and cultural connotation. The cultural quality and cultural image can be improved through the excavation of the local traditional cultural connotations. With the rapid social and economic development, people will be more and more aware of the protection of national cultural resources, so in the latter part of the corresponding work, to show a certain degree of systemic and integrity, people can more in-depth and comprehensive understanding of the local of the national culture.

\section{The development strategy of tourism and cultural resources in southwest minority areas}

\subsection{The guiding ideology}

Because of the rich cultural resources of tourism in south-western minority areas of our country, and showing the characteristics of regional pattern, we should establish a new concept of large-scale development, large resources, big market and large tourism in the development of tourism cultural resources, the tourism industry as a local Of the primary industry to develop and nurture, to achieve a leap-style breakthrough, the local rich resources as the basis of superiority, to take unconventional development model, according to the source market, to indepth excavation of national cultural tourism quality, to improve economic efficiency for the development centre, by grasping the characteristics, focus, macro-control and scientific guidance to achieve the depth of development, the south-western region of the tourism and cultural resources for rational distribution. For now, the development of the breakthrough is the main characteristics of tourism projects, tourism products to create characteristics series, to form a unique attraction, and increase the expansion of the national 
market. In order to achieve long - term development, we should also pay attention to the scientific and cultural connotation of tourism products to enhance and strengthen participation in tourism and high - grade independent tourism activities in the early development and management of the latter part of the government should play a leading role.

\subsection{The development goals}

The ultimate goal of the exploitation of tourism cultural resources in the southwest minority areas is to make the southwest area of our country a unique national and cultural tourist destination both at home and abroad. On the current tourism industry, has been gradually to the "circle" direction, so the southwestern region to carry out tourism development should also be around a group of points to the integrated development of multiple tourist routes, breaking the geographical restrictions, so natural Can enrich the local tourism and cultural resources, in the development process can fully learn from the "Suhanghang", "Guangdong, Hong Kong and Macao", "Xinmatai" and other places of successful experience. In order to improve the rationality and scientific development of the tourism cultural resources in the southwest minority areas, it is necessary to formulate the development goals in stages and carry out step by step.

The recent: from $2017-2022$ can be used as the south-western region of tourism and cultural resources development infrastructure, the tourism industry as a local pillar industry and the new economic growth point to nurture, in the development and management of the full play the government's dominant advantage. First of all, sort out the relationship between each other, select the main tourism development projects, can increase the minority museums, folk customs and folk customs, such as village construction with national characteristics. For this stage, the most important thing is the need for scientific planning, strengthen management, so as not to overlap in the late development of ideas or a single, repeat the layout of tourist attractions and other issues.

In the long-term: from 2022 - 201-2027 can be used as the south-western region is the focus of tourism and cultural resources development and construction period, through the expansion of funding channels, inline outside cited to promote the further improvement of management models, create a series Of national culture, scientific expedition, tourism education base and the national characteristics of tourism and cultural quality base, playing a national tourist attractions. Comprehensive and reasonable development of local national cultural resources, the construction of a complete national cultural tourism circle, build a number of tourist hotline, effective integration of local tourism and cultural resources, to achieve long-term development.

\subsection{The development strategy}

If you want to effectively develop the tourism and cultural resources of the southwest ethnic areas, the most critical is the need to develop a corresponding tourism development planning, the development of reasonable planning steps to ensure its scientific and rational. For the southwest region, both in the tourist 
attractions, or in tourism resources, are very rich, well-known, resources and traffic three basic conditions are already available, can effectively create a "tourism circle." Through reasonable planning, we can provide effective guidance to the late development work, prevent duplication and construction of low-grade scenic spots; secondly, it will help each region to coordinate development with each other and attract more capital investment.

Through regional linkage, can be a good common plate, creating a regional brand, to jointly build and create a good atmosphere of the tourism environment. To ensure that tourism development has always been in a healthy and normal development track, to avoid mutual squeeze, vicious competition and the emergence of self-government and other undesirable phenomena, to achieve common development.

\section{Conclusion}

Overall, Chinese southwest region is very rich in tourism resources and whether it is the natural environment or the human environment both have a greater attraction for tourists. In the course of exploiting tourism resources in southwest minority areas, the most critical need is to formulate a reasonable tourism development plan, and gradually develop local tourism cultural resources, so as to realize the long-term development of tourism and promote the long economic development, develop and improve people's living standards and quality.

\section{References}

[1] Yang De-jin, Bai Chang-hong, Niu Hui-cong. Policy and Path of Development of Responsible Tourism in Poverty Alleviation in Ethnic Areas, Human Geography, 55(12), pp.68-70, 2011

[2] Zhong Jie. Study on Tourism Development Strategy of Sichuan Ethnic Region Based on Tourism Resources Evaluation - A Case Study of Ganzi Tibetan Autonomous Prefecture. Land and Natural Resources Research, 8 (5), pp.87- 91, 2013

[3] Lam Ming-ying. Discussion on the Strategies and Paths of the Development of Cultural and Tourism Integration in the Ethnic Areas of Western Sichuan Plateau. Journal of Southwest University for Nationalities (Humanities and Social Sciences), 12(10), pp. 18- 20, 2012

[4] Zeng $\mathrm{Yu} \mathrm{Xi}$, Yang Xiaoxia .Southeast Chongqing ethnic minority areas tourism poverty alleviation strategy choice. Journal of Chongqing University of Arts and Sciences (Social Science Edition), 9(6), pp.58- 61, 2011

[5] Fu Jing-bao. Choice of Eco-tourism Development Strategy in Southwest Ethnic Region - Based on SWOT Analysis. Journal of Southwest University for Nationalities (Humanities and Social Sciences), 8(4), pp.85-87, 2014 